\title{
Article \\ Electrophoretic Deposition of a Hybrid Graphene Oxide/Biomolecule Coating Facilitating Controllable Drug Loading and Release
}

\author{
Jun-Sung Oh $\mathbb{( D}$, Jun-Hwee Jang $(\mathbb{D}$ and Eun-Jung Lee *(D)
}

Citation: Oh, J.-S.; Jang, J.-H.; Lee, E.-J. Electrophoretic Deposition of a Hybrid Graphene

Oxide/Biomolecule Coating Facilitating Controllable Drug Loading and Release. Metals 2021, 11, 899. https://doi.org/10.3390/met 11060899

Academic Editor: Hyun-Do Jung

Received: 16 April 2021

Accepted: 28 May 2021

Published: 31 May 2021

Publisher's Note: MDPI stays neutral with regard to jurisdictional claims in published maps and institutional affiliations.

Copyright: (c) 2021 by the authors. Licensee MDPI, Basel, Switzerland. This article is an open access article distributed under the terms and conditions of the Creative Commons Attribution (CC BY) license (https:// creativecommons.org/licenses/by/ $4.0 /)$.
Department of Nano-Biomedical Science \& BK21 PLUS NBM Global Research Center for Regenerative Medicine Dankook University, Cheonan 31116, Korea; gda4101@dankook.ac.kr (J.-S.O.); junhweej@dankook.ac.kr (J.-H.J.)

* Correspondence: leeej@dankook.ac.kr; Tel.: +82-41-550-3697

\begin{abstract}
Two-dimensional (2D) graphene oxide (GO) exhibits a high drug loading capacity per unit mass due to its unique structure and hydrophilicity and has been widely researched for drug-delivery systems. Here, we modified the surfaces of metal implants; we applied GO-based coatings that controlled drug loading and release. We used electrophoretic deposition (EPD) to apply the coatings at room temperature. The EPD coatings were analyzed in terms of their components, physical properties such as hardness and hydrophilicity, and in vitro cell tests of their biological properties. Uniform GO-EPD coatings improved surface hydrophilicity and hardness and greatly improved the bone differentiation properties of the metal substrate. Drug loading and release increased greatly compared to when the drug was adsorbed to only the surface of a coating. GO facilitated deposition of a drug-containing coating via EPD, and the surface modification, and drug loading and release, were controlled by the thickness of the coating.
\end{abstract}

Keywords: graphene oxide; electrophoretic deposition; implant; biomolecule; complex

\section{Introduction}

Metals are widely used to replace damaged bones, especially load-bearing bones [1] Any metal is a bioinert material, the use of which raises concerns about (poor) biocompatibility, inappropriate mechanical properties, and inflammatory/immune reactions caused by metal ion dissolution [2]. Surface modifications of dental or orthopedic metal-based implants enhance biocompatibility and functionality [3,4]. Surface treatments may be physical, chemical, or biological in nature. Physical methods may alter the surface morphology to induce attachment to regenerated bone, or oxidize the implant surfaces to increase hydrophilicity and reduce corrosion caused by micro-arc oxidation and anodizing [5]. Chemical methods alter the surface of implants without significantly affecting their bulk properties, yielding hard, wear-resistant hydrophilic surfaces. The various techniques include chemical vapor deposition (CVD), plasma vapor deposition (PVD), ionbeam deposition (IBAD), grafting techniques, and the use of self-assembling monolayers (SAMs) [6-9]. Biological methods effectively improve the biological properties of bioinert metal implants [10].

Synthetic biomimetic strategies enhancing the functionality of metal-based implants have focused principally on the addition of biomolecules to implant surfaces. Growth factors and protein-mimetic peptides improve the interactions between the implant and the biological environment, with preservation of the bulk implant's mechanical properties [11]. Reactive groups are required for biomolecular tethering. However, bioinert metal surfaces lack such groups. Surface active groups (e.g., $-\mathrm{OH},-\mathrm{COOH}$, and $-\mathrm{NH} 2$ ) are essential for surface modification. Oxygen-terminal carbon-based materials facilitate strong physisorption of biomolecules to carbon-based materials [12]. 
Graphene oxide (GO) contains several reactive oxygen groups (e.g., $\mathrm{C}=\mathrm{O}, \mathrm{COOH}$, $\mathrm{OH}$, and $\mathrm{C}-\mathrm{O}-\mathrm{C}$ ), suspends well in water, and interacts with biomolecules and drugs. The unique flake-type two-dimensional (2D) structure is associated with high drug loading per unit of GO mass; the GO surface area is high. GO exhibits good mechanical properties, good biocompatibility (especially in terms of osteoconductivity), and good antimicrobial activity. GO is an optimal coating for orthopedic implants [13,14]. There are many reports that carbon-based materials, such as graphene, combined with biomolecules (BM) are effective in regenerating bone tissue. Examples include complexes of carbon-based materials with BM such as BMP-2, FGFs, and Simvastatin [15-17]. In addition, these complexes have been produced in various forms, including film, coating, particles, scaffolds, and fibers, and the properties analyzed and widely applied in implants research for tissue regeneration [18-21]. Biomimetic surface modifications enhance implant function; however, biomolecules are vulnerable to high temperatures, strong acid/base conditions, and chemical solvents [22]. Therefore, many studies use natural biopolymers as a base material that can be processed in aqueous conditions to prevent the stability of biomolecules, or incorporate biomolecules after the fabricating process of base materials is completed [21,23]. In particular, the surface modifications of metal implants require the gentle condition for all processes including the preparation of BM-combined composites and deposition of them on the surface. The electrophoretic deposition (EPD) method can be used to form coatings from aqueous solutions at room temperature. EPD deposits colloidal particles in an aqueous electrolytic bath onto substrates. The coating time is short, and the coatings are uniform and continuous $[24,25]$. EPD has been used to produce graphene films, graphene-based reinforced composites, complex materials, interleaved porous structures, and nanoparticlespaced graphene films [26]. To modify the surfaces of implants used for hard-tissue engineering, researchers have sought to reduce internal corrosion, increase hardness, and enhance biocompatibility by the addition of biopolymers; however, few studies have explored combinations of $\mathrm{GO}$ with therapeutic drugs. We are the first to use EPD to develop GO-biomolecule (GO-BM) hybrid coatings of controllable thickness; the coatings contain large amounts of drugs. If BMs are exposed on an implant surface, an additional layer is required to protect the BMs from loss or denaturation during transplantation. Our method reduces BM damage and allows control of drug loading and release. It is a technology applicable to drug-eluting stents or orthopedic implants development, which is expected to lead to enhanced therapeutic effects. In this study, GO-EPD coatings for biomedical applications were evaluated in terms of composition, physical properties, cellular interactions, and drug release [27-30].

\section{Materials and Methods}

\subsection{Materials}

Titanium plates (bare Ti of grade 2, Titanart, Incheon, Korea) served as EPD substrates. The plates were polished with 800- and 1200-grit silicon carbide paper and ultrasonically cleaned in acetone, ethanol (Duksan, Ansan, Korea), and distilled water (5 min for each bath). Single-layer GO was from Graphene Supermarket (Ronkonkoma, NY, USA). Ethanol (Duksan, Ansan, Korea) was 99.6\% pure. Green fluorescence protein (GFP) and bone morphogenic protein-2 (BMP-2) were supplied by Genoss, Gyeonggi-do, Korea.

\subsection{Electrophoretic GO Deposition}

A GO suspension $(500 \mu \mathrm{g} / \mathrm{mL})$ was prepared in $80 \%(v / v)$ ethanol and sonicated for $15 \mathrm{~min}$. Ti plates were submerged in the suspension at $1 \mathrm{~cm}$ from the cathode, and EPD proceeded at $10 \mathrm{~mA}$ for $1 \mathrm{~min}$. The plates were then dried and stored in a desiccator. Prior to biological tests, the coated plates were sterilized with 70\% $(v / v)$ ethanol. EPD was also used to prepare drug-eluting coatings; the test BMs were GFP and BMP-2. Various amounts of the BMs $(10,25,50$, and $100 \mu \mathrm{g} / \mathrm{mL})$ were added to GO suspensions or GO-coated Ti plates, magnetically stirred for $3 \mathrm{~h}$, and EPD was performed or drug release was assessed. 


\subsection{Characterization}

The surface morphology and coating thicknesses were studied via scanning electron microscopy (SEM; JSM-6510, JEOL Ltd., Tokyo, Japan). X-ray diffraction (XRD; Ulima IV, Rigaku, Tokyo, Japan) was used to define the phase compositions of Ti and GO-coated Ti. The test voltage was $40 \mathrm{kV}$ and the current was $40 \mathrm{mV}$; $\mathrm{Cu}-\mathrm{K} \alpha$ radiation was delivered $\left(\lambda=1.540598 \AA\right.$ ) over a $2 \theta$ range of $5-70^{\circ}$ with a step size of $1^{\circ}$ and a count time of 1 $\mathrm{min} / \mathrm{step}$. A Raman spectroscopy (DXR2xi, Thermo Fisher, Waltham, MA, USA) was performed at $532 \mathrm{~nm}$. Zeta potentials were measured using a Zetasizer (Nano-ZS, Malvern Instruments, Malvern, UK) with water as the dispersant. The electrophoretic mobilities of suspensions were converted to zeta potentials. An X-ray photoelectron spectroscopy (XPS; Axis Supra, Kratos, UK) was performed with the aid of focused, monochromatized $\mathrm{Al}$ Ka radiation $(\mathrm{h} v=1486.6 \mathrm{eV})$. An atomic force microscope (AFM) (Bruker Dimension Edge, Middlesex County, MA, USA) was used to characterize surface microstructure and morphology. Coating hardness was measured using a Vickers indenter (HM-221, Mitutoyo, Kanagawa, Japan) at a load of 0.98 N. Contact angles (D7334-08 device, ASTM, Montgomery County, PA, USA) were used to measure the surface wettabilities of Ti and GO-coated Ti plates.

\subsection{BM Loading and Release}

$\mathrm{BM}(100 \mu \mathrm{g} / \mathrm{mL})$ loading and release into/from GO before and after GO-EPD were evaluated by visualizing the GFP via confocal laser scanning spectroscopy (CLSM, ZeissLSM510, Carl Zeiss, Oberkochen, Germany). The extent of fluorescence reflected the BM level. BM loaded onto and then released from GO-BM/Ti coatings was measured by ELISA after immersing the complexes in phosphate-buffered saline (PBS) pH 7.4 at $37^{\circ} \mathrm{C}$ for up to 20 days. The PBS was replaced at defined intervals. The released BM levels were measured by deriving optical absorbances at $490 \mathrm{~nm}$ using a microplate reader (SpectraMax M series, Molecular Devices, San Jose, CA, USA).

\subsection{Cell Morphology}

For the in vitro cell tests, mesenchymal stem (mMSC) cells were isolated from mouse (5 weeks, male) bone marrow harvested from the tibia and femoral marrow compartments, then cultured in general cell media, utilizing Dulbecco's Modified Eagle's Medium (DMEM, Welgene, Gyeongsan, Korea) supplemented with 10\% fetal bovine serum (FBS, Gibco, Eri County, NY, USA), and 1\% penicillin/streptomycin (P/S, ThermoFisher, Waltham, MA, USA) at $37{ }^{\circ} \mathrm{C}$, with $5 \% \mathrm{CO}_{2}$, and at $90 \%$ humidity. Cells were seeded onto Ti and GOcoated Ti plates at $1 \times 10^{4}$ cells $/ \mathrm{mL}$. After being cultured for $4 \mathrm{~h}$ or 3 days, cells were fixed in $4 \%(v / v)$ paraformaldehyde (Sigma-Aldrich, St. Louis, MO, USA) with Triton X-100 for $10 \mathrm{~min}$ and rinsed three times in PBS. Then, $200 \mu \mathrm{L}$ of Alexa 647 (red) and 488 (green) solutions (Thermo Fisher Scientific, Waltham, MA, USA) were added to each well followed by incubation for $1 \mathrm{~h}$. The stained cells were rinsed three times with PBS and observed under a confocal laser scanning microscope.

\subsection{Alkaline Phosphatase (ALP) Activity}

Alkaline phosphatase (ALP) activity was measured after 7 days of culture using the para-nitrophenyl phosphate assay (Takara, Tokyo, Japan) according to the manufacturer's protocol. Cells were washed in DPBS and lysed in $0.1 \%(v / v)$ Triton X-100. Proteins in the extracts were quantified using a BCA protein assay kit (Takara, Tokyo, Japan). The absorbance of the reaction product was measured at $405 \mathrm{~nm}$. ALP activity was normalized to the total protein content.

\subsection{Alizarin Red S Staining to Detect Mineralization}

Alizarin Red S (ARS) staining was used to detect extracellular calcium deposits generated by 14 days. Cells were washed twice in DPBS, fixed in $4 \%(v / v)$ paraformaldehyde for $15 \mathrm{~min}$, and stained with $2 \%(w / v)$ ARS solution ( $\mathrm{pH} 4.2)$. The cells were then washed 
three times with distilled water and dried at room temperature. Mineralization-positive cells were stained red. To quantify staining, the stain was extracted into $10 \%(v / v)$ acetic acid for $30 \mathrm{~min}$, followed by neutralization (ammonium hydroxide), and the absorbances were read at $405 \mathrm{~nm}$.

\subsection{Statistical Analysis}

The quantitative results of the in vitro cell tests were collected in at least three replicates from each test group. The statistical analyses were performed using a t-test, and comparisons between groups were analyzed by a one-way analysis of variance test. The differences with a $p$ value $<0.05$ were considered statistically significant $\left({ }^{*} p<0.05\right)$.

\section{Results and Discussion}

\subsection{Preparation of GO-Coated Ti Plates}

GO-coated Ti plates were prepared via EPD at room temperature. A schematic is shown in Figure 1a. Hydrophilic GO bound BMs between the many GO layers (Figure 1b) [31]. Prior to EPD, BM was conjugated onto GO sheets and the complexes were evenly dispersed in electrolytic baths with $80 \%(v / v)$ ethanol; EPD followed. The GO coatings thus contained internal BM. The schematic of Figure $1 \mathrm{~b}$ shows how BM was attached after the GO coating. The GO coating thickness can be controlled when modifying metal implants; the coating can contain large amounts of BM. If the BM were to be exclusively surface-attached, a protective layer would be required. Our method removed the need for such a layer [32].

(a)

Combination of GO-biomolecules (BM)

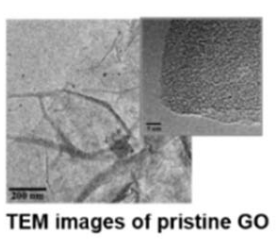

(b) Post-BM/Ti
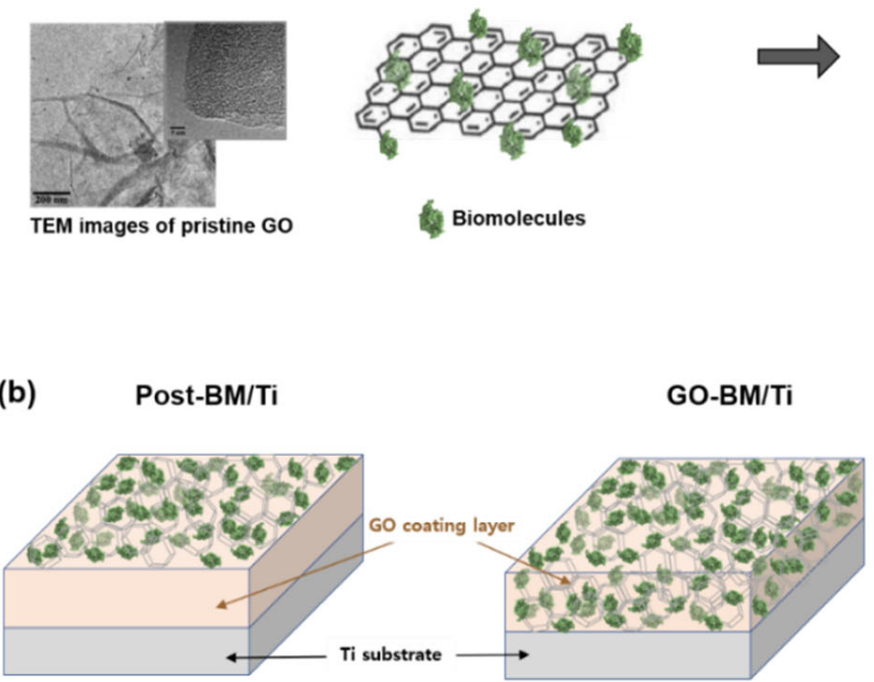

Preparation of electrolytic bath

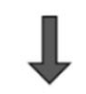

Electrophoretic deposition

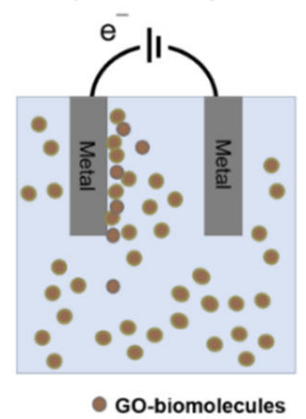

Figure 1. Schematic diagram of electrophoretic deposition (a). The coating layers termed Post-BM/Ti and GO-BM/Ti (b).

\subsection{Characterization of GO-Coated Ti Plates}

GO coating morphology and thickness depend on the EPD time, voltage, current, and GO concentration. Figure $2 \mathrm{a}$ shows photographs of bare Ti and GO-coated Ti plates. After EPD, the Ti substrate was uniformly covered with brown GO. Figure $2 b, c, e$ shows SEM images of bare and GO-coated Ti plates; a short deposition time created thin films and a long deposition time created thick films. 
(a)

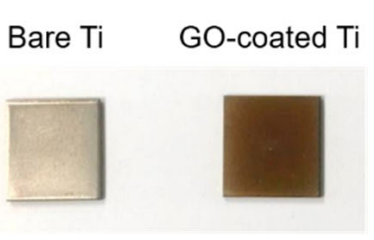

(c)

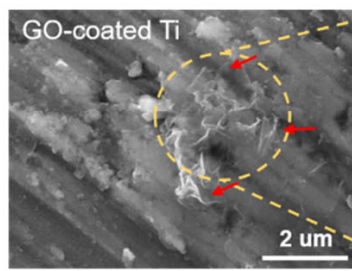

(e)

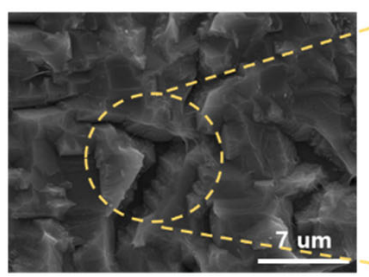

(b)

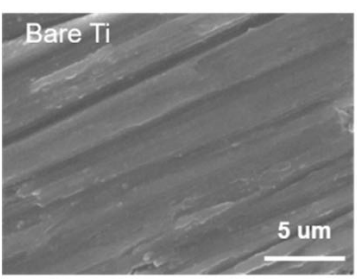

(d)
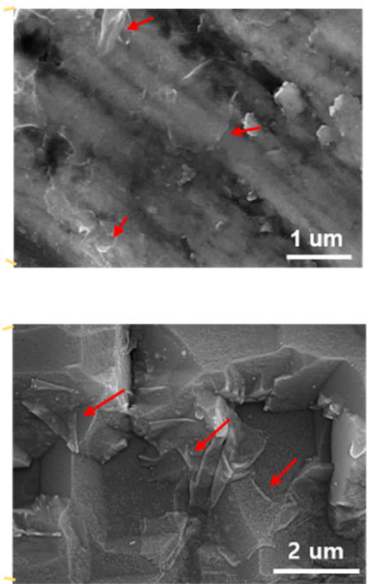

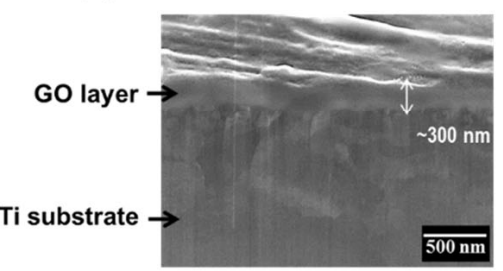

(f)

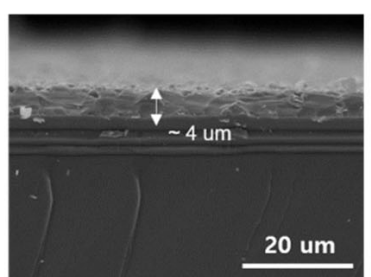

Figure 2. Optical surface images (a). SEM image of a bare Ti surface (b). Images of Ti plates coated thinly and thickly with GO (the arrows indicate GO flakes) (c,e). Cross-sectional views of thin and thick GO coatings $(\mathbf{d}, \mathbf{f})$.

Figure 2c,e shows the morphologies of (smooth) bare and GO-coated Ti plates. Crosssections were prepared to measure coating thickness by EPD time. Increasing the time from 30 to $600 \mathrm{~s}$ increased the coating thickness. Figure $2 \mathrm{~d}$ shows that the 30 -s layer was less than $300 \mathrm{~nm}$ thick; Figure $2 \mathrm{f}$ shows that the 10-min thickness was approximately $4 \mu \mathrm{m}$.

The coated GO layer was analyzed by X-ray photon and Raman spectroscopy, and an X-ray diffraction analysis. The XPS spectra of GO-coated and bare Ti revealed titanium (Ti2p), oxygen (O1s), and carbon (C1s) (Figure 3a). The O1s peak was attributable to adsorbed hydroxides and oxides; both specimens showed peaks at $531.9 \mathrm{eV}$. The Ti2p3/2 oxide peak at $458.5 \mathrm{eV}$ was typical of Ti. The $\mathrm{C} 1 \mathrm{~s}$ peak was most often used to measure oxide levels, but the peak was weak for bare Ti. The C1s of GO featured several binding energy configurations, at 284.8, 285.1, 286.3, and $288 \mathrm{eV}$ for sp2, sp3, and the C-O (epoxy/hydroxyl), and $\mathrm{O}-\mathrm{C} 5 \mathrm{O}$ (carboxyl) groups, respectively. The sp2 carbon $(284.8 \mathrm{eV}$ ) was the major feature of the $\mathrm{C} 1 \mathrm{~s}$ profile, indicating the presence of $\mathrm{GO}$, which was generally identified by the three characteristic Raman G, D, and 2D bands [33]. The Raman spectrum of GO showed the D band (sp3) at $1350 \mathrm{~cm}^{-1}$ and $1344 \mathrm{~cm}^{-1}$ and the $\mathrm{G}$ band (sp2) at $1604 \mathrm{~cm}^{-1}$ and $1601 \mathrm{~cm}^{-1}$; bare Ti lacked these bands (Figure 3b) [34]. Figure 3c shows the XRD patterns. The typical diffraction peaks of Ti (those of the JCPDS card no. 44-1294) were observed. GO-coated Ti exhibited a broad peak at $26^{\circ}$, indicating between-graphene $\pi-\pi$ stacking [35]. Hexagonal crystals of graphene or graphite were associated with characteristic peaks in the (002) and (111) planes [36]. Thus, GO clearly coated the Ti, and EPD rendered the coating uniform and thickness controllable.

Figure $4 \mathrm{a}, \mathrm{b}$ shows the contact angle hydrophilicities and indentation hardness values, respectively. GO coating dramatically improved Ti hydrophilicity and hardness, reflecting the outstanding mechanical properties (Young's modulus 1 Ta) of GO [37-39]. When metal-based implants are transplanted, strong friction and shear stresses can damage their surfaces [40]. Many coatings have been used to strengthen the surfaces [41]. Here, we simply coated GO using EPD. 
(a)

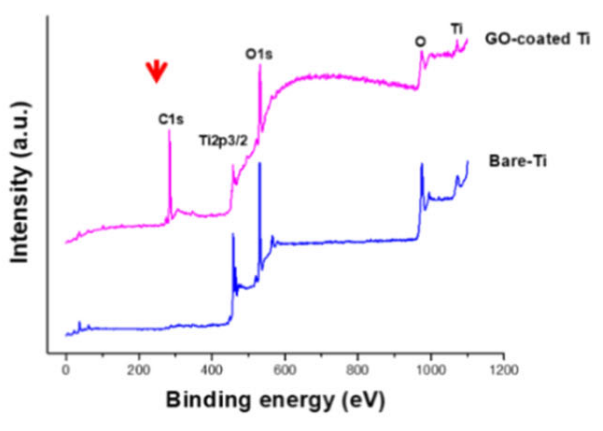

(b)

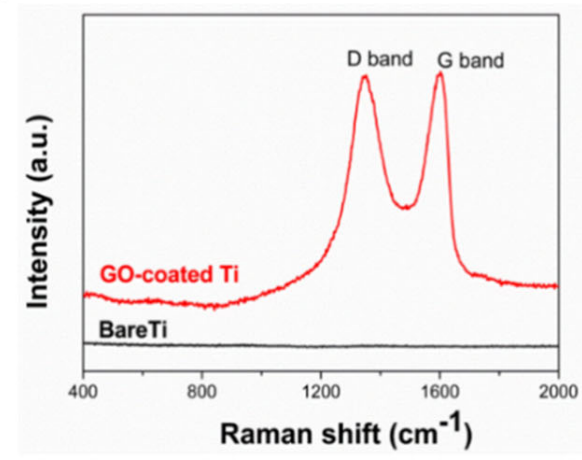

(c)

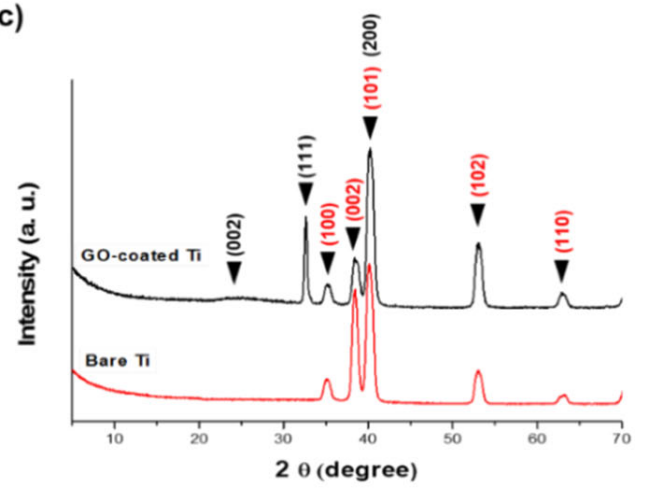

Figure 3. EPD characterization of GO-coated Ti and bare Ti. XPS spectra (a). Raman spectra (b). XRD patterns (c).

(a)

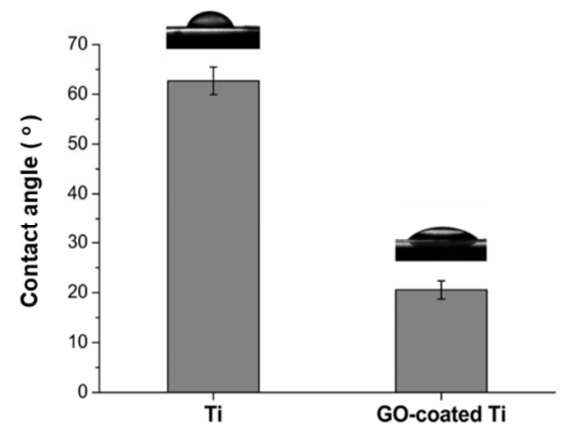

(b)

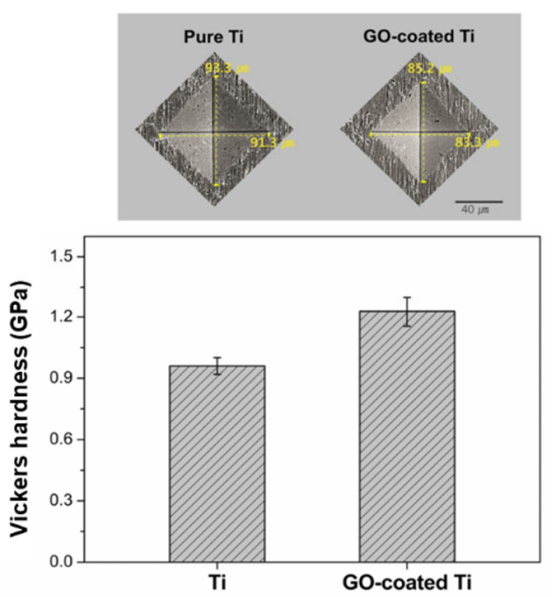

Figure 4. Contact angles (a) and Vickers hardness values (b) of bare and GO-coated Ti $(p<0.05)$.

\subsection{In Vitro Cellular Responses}

GO exhibited good biocompatibility and osteo-conductivity; we used CLSM to evaluate the effects of coating on stem cells, and the extents of ALP activity and mineralization compared to those of bare Ti [42-44]. Figure 5a shows CLSM images of cells cultured for 3 days. The cells were well attached, spread by $4 \mathrm{~h}$, and grew over the 3 days. Neither cell attachment nor proliferation differed between the samples. To evaluate the initial (and later) osteogenic differentiation of stem cells cultured on a GO-EPD layer, cells were cultured for 7 and 14 days in a non-osteogenic culture medium. Cellular ALP activity was significantly enhanced by the GO coating. After 14 days of culture, the cellular calcium levels were measured (Figure 5c). Cells cultured on GO-coated Ti exhibited slightly more calcium deposition than those cultured on bare Ti. Not only was GO-coated Ti non-toxic but also GO facilitated early osteogenic differentiation [42-44]. 
(a)

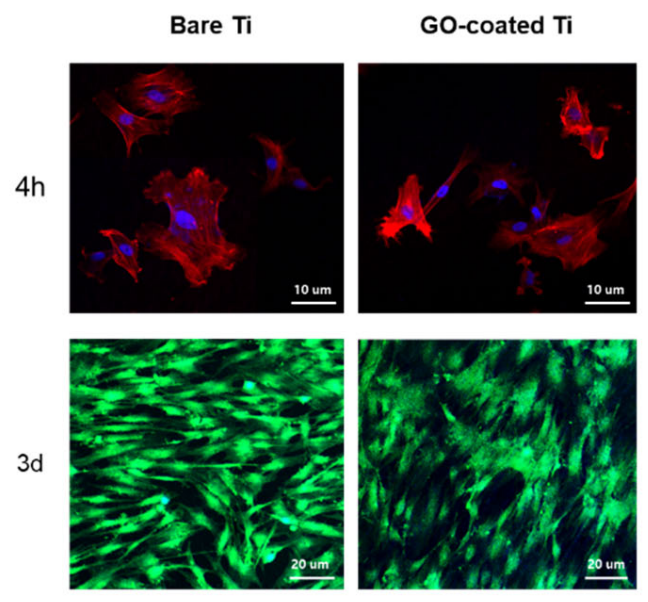

(b)

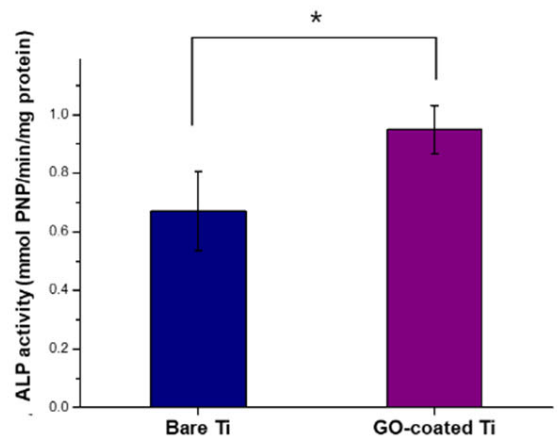

(c)

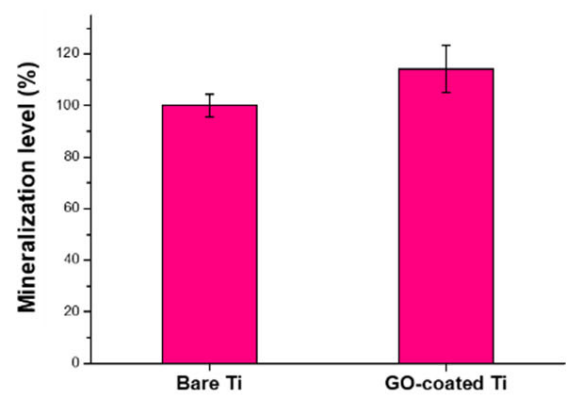

Figure 5. In vitro cell test results. Cell attachment revealed by CLSM (a). Alkaline phosphatase (ALP) activity of mMSCs after 7 days of culture (b). Alizarin Red S (ARS) staining after 21 days of culture $\left({ }^{*} p<0.05\right)(\mathbf{c})$.

\subsection{BM-Loading GO}

GO served as both the BMP-2 loading agent and the coating. 2D flaked GO readily binds BMs; the carbon honeycomb induces BM adsorption driven by the Van der Waals force [45]. After attachment of various levels of BMP-2 to GO, BMP-2 adhesion to GO was assessed by the AFM, the Zetasizer, ELISA, and XPS. An AFM is usually employed to measure graphene thickness. As shown in Figure $6 \mathrm{a}$, a blue line across the single graphene is specified and the roughness of the specimen is measured along the line. Figure $6 \mathrm{a}$ shows the representative AFM images of pristine GO and BM-combined GO. The AFM analysis was performed to observe the thickness change of GO combined with BM (BMP-2). The $\mathrm{Rz}$ value of GO and GO-GM were $4.10 \pm 0.26 \mathrm{~nm}$ and $5.74 \pm 0.61 \mathrm{~nm}$, respectively. This was an increase in thickness induced by BMP-2, indicating that GO and BMP-2 were well combined.

Figure $6 \mathrm{~b}$ shows the zeta potentials of GO with different BMP-2 concentrations; all GO coatings were deposited on the positively charged electrode. The zeta potential confirmed that EPD was in play, and that the GO and BM combination was efficient. The negative GO potential facilitated BMP-2 attachment. At a high concentration of BMP-2, the GO-BM zeta potential became more electropositive. Thus, BMP-2 adsorption to GO increased with increasing BMP-2 concentration, but the GO-BM potential remained negative; there was no need to switch the EPD anode and cathode. Figure $6 \mathrm{c}$ shows that at concentrations of 25 and $50 \mu \mathrm{g} / \mathrm{mL}$, approximately $85 \%$ of BMP-2 became attached; the absolute concentrations of unattached BMP-2 were approximately 3.7 and $7.5 \mu \mathrm{g} / \mathrm{mL}$, respectively. To minimize BMP-2 wastage, we used a BMP-2 concentration of $25 \mu \mathrm{g} / \mathrm{mL}$ in subsequent experiments. XPS revealed the components of the GO-BM coating (Figure $6 \mathrm{~d}$ ). The $\mathrm{C}$ peak and $\mathrm{O}$ peak of GO-coated Ti and GO-BM-coated Ti appeared at 285 and $532 \mathrm{eV}$ of binding energy, respectively. Compared to GO-coated Ti, GO-BM-coated Ti (Figure 6d) exhibited a higher 
$\mathrm{N} 1$ s peak at $399 \mathrm{eV}$, attributable to the $-\mathrm{C} 5 \mathrm{~N}$ or $-\mathrm{CN}$ bonds caused by the $\mathrm{N}$ atom in the amino acid of BMP-2 [46,47].

(a)

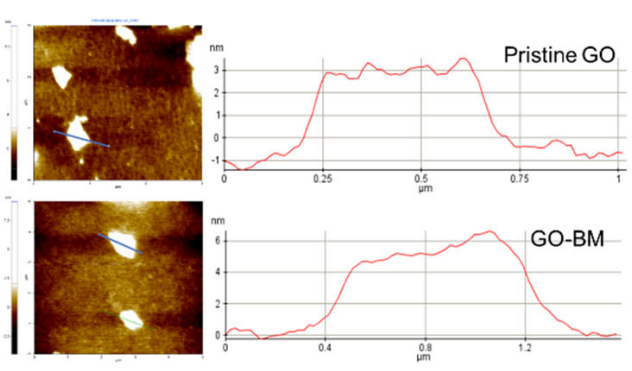

(c)

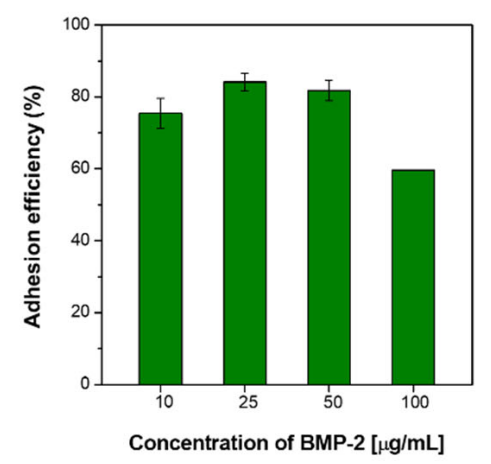

(b)

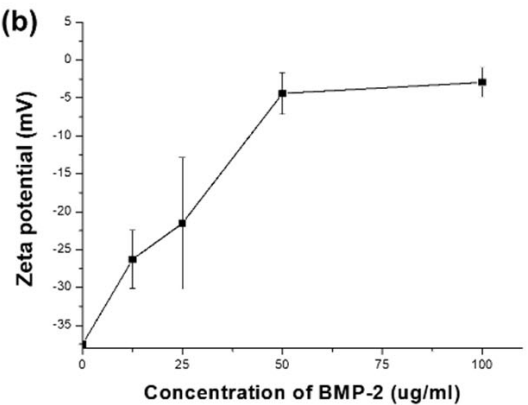

(d)

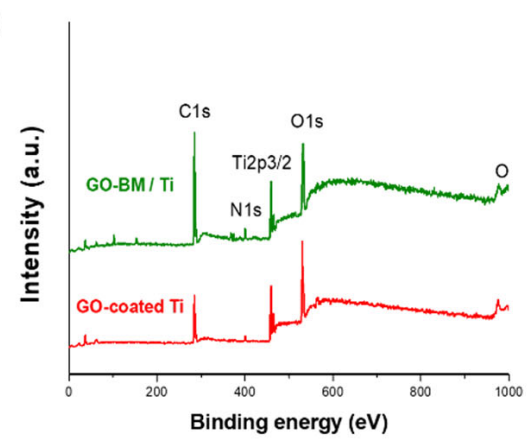

Figure 6. AFM observations of pristine GO and BM-combined GO (GO-BM) (a). The zeta potential of BM-combined GO as a function of the BMP-2 concentration (b). Characterization of GO-BM combinations by ELISA (c). XPS spectra of Ti with GO-BM coatings (GO-BM/Ti) and GO-coated Ti (d). The BM indicates BMP-2.

The GO-BM (BMP-2) coating layer was evaluated in more detail using XPS (Table 1). $\mathrm{Ti}, \mathrm{C}, \mathrm{O}$, and $\mathrm{N}$ were detected in bare Ti, and the GO and GO-BM coatings; however, the $\mathrm{N}$ atomic ratio was highest in the latter coating. While the Ti and $\mathrm{O}$ proportions fell significantly in the GO-BM coating, the $\mathrm{C}$ proportion was higher than those of other surfaces. Most biomolecules have amine and carboxyl groups; the $\mathrm{N}$ and $\mathrm{C}$ levels were thus highest in the GO-BM coating, indicating that EPD successfully formed such a coating [48].

Table 1. XPS component analyses of coating layers.

\begin{tabular}{llll}
\hline Amount (At. \%) & Bare Ti & GO & GO-BM \\
\hline $\mathrm{Ti}$ & 13.45 & 9.88 & 5.1 \\
$\mathrm{C}$ & 44.57 & 51.3 & 64.5 \\
$\mathrm{O}$ & 39.79 & 35.69 & 26.59 \\
$\mathrm{~N}$ & 2.17 & 3.13 & 3.82 \\
\hline
\end{tabular}

EPD forms uniform coatings. We compared GO-GFP, GO-BM, GO-coated Ti, and bare Ti. Figure 7 shows BM adhesion both photographically and as revealed by CLSM (Figure $7 \mathrm{a}-\mathrm{c}$ ). Compared to bare $\mathrm{Ti}, \mathrm{GO}-\mathrm{coated}$ layers had weak green fluorescence. To observe the surface of GFP-containing GO, we used adhesive tape to separate the GO$\mathrm{BM}$ coating from bare Ti. The CLSM boundary data of Figure 7c show that more green fluorescence emanated from the BM-coated region. The weak green fluorescence of bare Ti may indicate that the GO-BM (GFP) suspension penetrated the adhesive tape during EPD. Unlike the surface of GO-coated Ti, a surface coated with GO-BM exhibited strong fluorescence. SEM (Figure 7d) revealed aggregates (red arrows) on the GO-BM coating. The combination of two substances during GO-BM formation was associated with aggregation or sinkage. Thus, EPD featured continuous stirring that minimized sinkage but did not 
completely prevent aggregation. Therefore, the green fluorescent aggregates were thought to be GO-BM complexes.

(a)

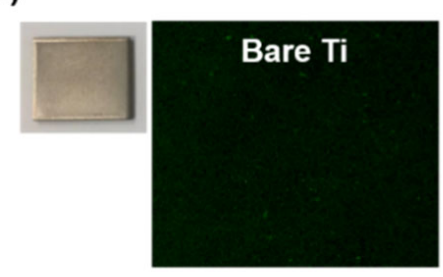

(c)

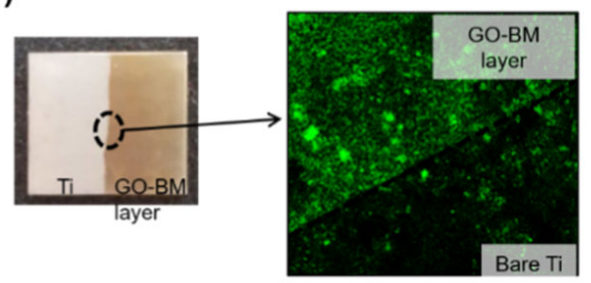

(b)

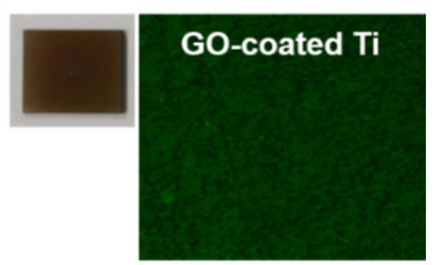

(d)

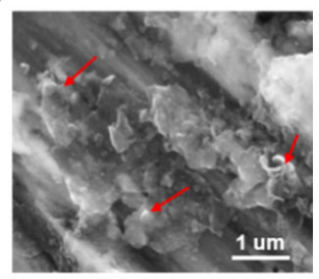

Figure 7. Optical and CLSM images of BM attachment: bare Ti (a), GO-coated Ti (b) , and GO$\mathrm{BM} / \mathrm{Ti}$ (c). CLSM evaluation of GO-BM/Ti was performed on a region with a GO-BM layer and a region of bare Ti. SEM image of Ti with a GO-BM coating $(\mathbf{d})$. The BM indicates GFP.

\subsection{BM Release from $\mathrm{GO}$-Coated $\mathrm{Ti}$}

BM release was assessed via CLSM and ELISA. Figure 8a shows fluorescence images of $\mathrm{BM}$ that remained in the GO-BM coating after soaking for various times in PBS. Over 20 days, the fluorescence intensity fell continuously, indicating sustained BM release from the GO-BM coating layer. Figure $8 \mathrm{~b}$ shows the cumulative amounts of BM released over time. Ti exposed to BM after GO coating and Ti coated with the GO and BM combination are indicated by Post-BM and GO-BM respectively. BM was slowly and steadily released over an extended period. During up to 10 days $(240 \mathrm{~h})$ of analysis, both samples released similar amounts of BM. However, after 20 days, the total amounts of BM released from GO-BM/Ti and Post-BM/Ti were approximately 79.9 and $24.5 \mu \mathrm{g}$, respectively. CLSM revealed no significant reduction in fluorescence intensity during release up to 10 days; however, on day 14, major decreases in fluorescence intensity were evident, in line with the release profiles. After 10 days, $\mathrm{BM}$ was no longer released from the Post-BM/Ti sample; however, GO-BM/Ti then exhibited continued rapid BM release, unlike the previous steady release profile.

(a)

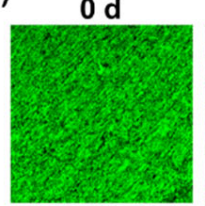

$10 \mathrm{~d}$

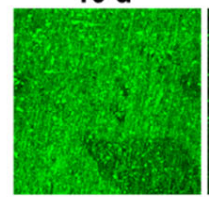

$3 \mathrm{~d}$

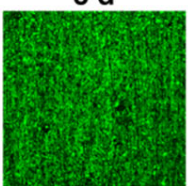

$14 \mathrm{~d}$

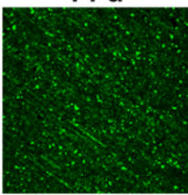

$7 d$

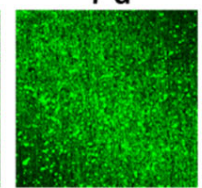

$20 \mathrm{~d}$

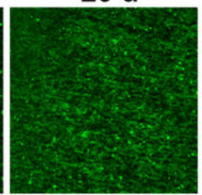

(b)

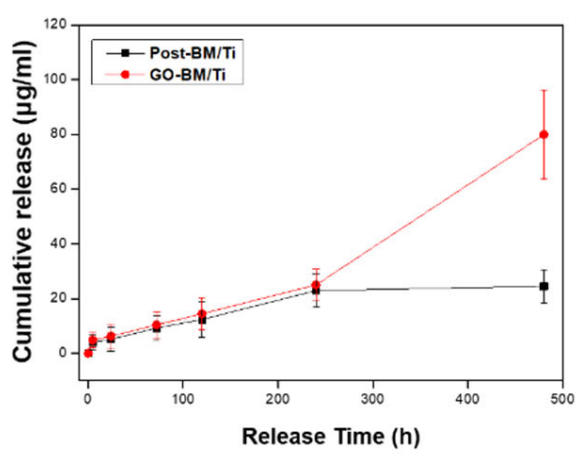

Figure 8. Release behaviors of BM (GFP). CLSM fluorescence images of BM remaining in GO$\mathrm{BM} / \mathrm{Ti}(\mathbf{a})$. BM release profiles over time $(\mathbf{b})$. 
We found that BM pervaded the coating, and we demonstrated how to modify metal implants to ensure stable long-term BM release. The coating thickness controlled the amount and rate of BM release. Room temperature EPD coated undamaged BMs; it was easy to adjust the coating thickness. GO readily adsorbed BMs. High-quality coatings of varying (controllable) thickness formed rapidly. BM loadings were high, because the BMs were not (only) surface-attached.

\section{Conclusions}

We used EPD to modify metal surfaces to stably and slowly deliver BMs. GO coating increased surface hydrophilicity and hardness and ALP activity (a feature of osteogenic differentiation). Hydrophilic GO combined with BMs to form GO-BM complexes that uniformly coated a metal. Coatings with internal (not only surface-attached) BMs were optimal, and will find many applications in medicine.

Author Contributions: Conceptualization, E.-J.L.; methodology, J.-S.O. and J.-H.J.; investigation, E.-J.L., J.-S.O. and J.-H.J.; writing—original draft preparation, E.-J.L., J.-S.O. and J.-H.J.; writingreview and editing, E.-J.L., J.-S.O. and J.-H.J.; supervision, E.-J.L.; project administration, E.-J.L.; funding acquisition, E.-J.L. All authors have read and agreed to the published version of the manuscript.

Funding: This work was supported by the National Research Foundation of Korea (NRF), which is funded by the Ministry of Science and Information and Communications Technologies (MSIT; NRF-2018M3C1B7021994 and NRF-2020R1A2C1012454).

Data Availability Statement: Not applicable.

Acknowledgments: This work was supported by the National Research Foundation of Korea (NRF), which is funded by the Ministry of Science and Information and Communications Technologies (MSIT; NRF-2018M3C1B7021994 and NRF-2020R1A2C1012454).

Conflicts of Interest: The author(s) declared no potential conflicts of interest with respect to the research, authorship, and/or publication of this article.

\section{References}

1. Alvarez, K.; Nakajima, H. Metallic scaffolds for bone regeneration. Materials 2009, 2, 790-832. [CrossRef]

2. Pizzoferrato, A.; Cenni, E.; Ciapetti, G.; Granchi, D.; Savarino, L.; Stea, S. Inflammatory response to metals and ceramics. In Integrated Biomaterials Science; Barbucci, R., Ed.; Springer US: Boston, MA, USA, 2002; pp. 735-791.

3. Shahali, H.; Jaggessar, A.; Yarlagadda, P.K.D.V. Recent advances in manufacturing and surface modification of titanium orthopaedic applications. Procedia Eng. 2017, 174, 1067-1076. [CrossRef]

4. Dong, H.; Liu, H.; Zhou, N.; Li, Q.; Yang, G.; Chen, L.; Mou, Y. Surface modified techniques and emerging functional coating of dental implants. Coatings 2020, 10, 1012. [CrossRef]

5. Kim, Y.-W. Surface modification of ti dental implants by grit-blasting and micro-arc oxidation. Mater. Manuf. Process. 2010, 25, 307-310. [CrossRef]

6. López, V.; Sundaram, R.S.; Gómez-Navarro, C.; Olea, D.; Burghard, M.; Gómez-Herrero, J.; Zamora, F.; Kern, K. Chemical vapor deposition repair of graphene oxide: A route to highly-conductive graphene monolayers. Adv. Mater. 2009, 21, 4683-4686. [CrossRef]

7. Vats, N.; Rauschenbach, S.; Sigle, W.; Sen, S.; Abb, S.; Portz, A.; Dürr, M.; Burghard, M.; van Aken, P.A.; Kern, K. Electron microscopy of polyoxometalate ions on graphene by electrospray ion beam deposition. Nanoscale 2018, 10, 4952-4961. [CrossRef] [PubMed]

8. Terasawa, T.-O.; Saiki, K. Growth of graphene on cu by plasma enhanced chemical vapor deposition. Carbon 2012, 50, 869-874. [CrossRef]

9. Wu, C.; Cheng, Q.; Sun, S.; Han, B. Templated patterning of graphene oxide using self-assembled monolayers. Carbon 2012, 50, 1083-1089. [CrossRef]

10. Beutner, R.; Michael, J.; Schwenzer, B.; Scharnweber, D. Biological nano-functionalization of titanium-based biomaterial surfaces: A flexible toolbox. J. R. Soc. Interface 2010, 7, S93-S105. [CrossRef] [PubMed]

11. Haimov, H.; Yosupov, N.; Pinchasov, G.; Juodzbalys, G. Bone morphogenetic protein coating on titanium implant surface: A systematic review. J. Oral. Maxillofac. Res. 2017, 8, e1. [CrossRef]

12. Ajori, S.; Ameri, A.; Ansari, R. Adsorption analysis and mechanical characteristics of carbon nanotubes under physisorption of biological molecules in an aqueous environment using molecular dynamics simulations. Mol. Simul. 2020, 46, 388-397. [CrossRef] 
13. Ouyang, L.; Deng, Y.; Yang, L.; Shi, X.; Dong, T.; Tai, Y.; Yang, W.; Chen, Z.-G. Graphene-oxide-decorated microporous polyetheretherketone with superior antibacterial capability and in vitro osteogenesis for orthopedic implant. Macromol. Biosci. 2018, 18, 1800036. [CrossRef]

14. Zhao, C.; Lu, X.; Zanden, C.; Liu, J. The promising application of graphene oxide as coating materials in orthopedic implants: Preparation, characterization and cell behavior. Biomed. Mater. 2015, 10, 015019. [CrossRef] [PubMed]

15. Hirata, E.; Ménard-Moyon, C.; Venturelli, E.; Takita, H.; Watari, F.; Bianco, A.; Yokoyama, A. Carbon nanotubes functionalized with fibroblast growth factor accelerate proliferation of bone marrow-derived stromal cells and bone formation. Nanotechnology 2013, 24, 435101. [CrossRef] [PubMed]

16. La, W.-G.; Park, S.; Yoon, H.-H.; Jeong, G.-J.; Lee, T.-J.; Bhang, S.H.; Han, J.Y.; Char, K.; Kim, B.-S. Delivery of a therapeutic protein for bone regeneration from a substrate coated with graphene oxide. Small 2013, 9, 4051-4060. [CrossRef] [PubMed]

17. Oh, J.-S.; Lee, E.-J. Enhanced effect of polyethyleneimine-modified graphene oxide and simvastatin on osteogenic differentiation of murine bone marrow-derived mesenchymal stem cells. Biomedicines 2021, 9, 501. [CrossRef]

18. Wu, J.; Zheng, A.; Liu, Y.; Jiao, D.; Zeng, D.; Wang, X.; Cao, L.; Jiang, X. Enhanced bone regeneration of the silk fibroin electrospun scaffolds through the modification of the graphene oxide functionalized by bmp-2 peptide. Int. J. Nanomed. 2019, 14, 733-751. [CrossRef]

19. Saladino, M.L.; Markowska, M.; Carmone, C.; Cancemi, P.; Alduina, R.; Presentato, A.; Scaffaro, R.; Biały, D.; Hasiak, M.; Hreniak, D.; et al. Graphene oxide carboxymethylcellulose nanocomposite for dressing materials. Materials 2020, 13, 1980. [CrossRef]

20. Li, H.; Gao, C.; Tang, L.; Wang, C.; Chen, Q.; Zheng, Q.; Yang, S.; Sheng, S.; Zan, X. Lysozyme (lys), tannic acid (ta), and graphene oxide (go) thin coating for antibacterial and enhanced osteogenesis. ACS Appl. Bio Mater. 2020, 3, 673-684. [CrossRef]

21. Han, L.; Sun, H.; Tang, P.; Li, P.; Xie, C.; Wang, M.; Wang, K.; Weng, J.; Tan, H.; Ren, F.; et al. Mussel-inspired graphene oxide nanosheet-enwrapped ti scaffolds with drug-encapsulated gelatin microspheres for bone regeneration. Biomater. Sci. 2018, 6 , 538-549. [CrossRef]

22. Oliver, J.-A.N.; Su, Y.; Lu, X.; Kuo, P.-H.; Du, J.; Zhu, D. Bioactive glass coatings on metallic implants for biomedical applications. Bioact. Mater. 2019, 4, 261-270. [CrossRef]

23. Santoro, M.; Tatara, A.M.; Mikos, A.G. Gelatin carriers for drug and cell delivery in tissue engineering. J. Control. Release 2014, 190, 210-218. [CrossRef] [PubMed]

24. Fox, K.E.; Tran, N.L.; Nguyen, T.A.; Nguyen, T.T.; Tran, P.A. 8—surface modification of medical devices at nanoscale-recent development and translational perspectives. In Biomaterials in Translational Medicine; Yang, L., Bhaduri, S.B., Webster, T.J., Eds.; Academic Press: Cambridge, MA, USA, 2019; pp. 163-189.

25. Besra, L.; Liu, M. A review on fundamentals and applications of electrophoretic deposition (epd). Prog. Mater. Sci. 2007, 52, 1-61. [CrossRef]

26. Ma, Y.; Han, J.; Wang, M.; Chen, X.; Jia, S. Electrophoretic deposition of graphene-based materials: A review of materials and their applications. J. Mater. 2018, 4, 108-120. [CrossRef]

27. Mallick, M.; Arunachalam, N. Electrophoretic deposited graphene based functional coatings for biocompatibility improvement of nitinol. Thin Solid Films 2019, 692, 137616. [CrossRef]

28. Eshghinejad, P.; Farnoush, H.; Bahrami, M.S.; Bakhsheshi-Rad, H.R.; Karamian, E.; Chen, X.B. Electrophoretic deposition of bioglass/graphene oxide composite on ti-alloy implants for improved antibacterial and cytocompatible properties. Mater. Technol. 2020, 35, 69-74. [CrossRef]

29. Mehrali, M.; Akhiani, A.R.; Talebian, S.; Mehrali, M.; Latibari, S.T.; Dolatshahi-Pirouz, A.; Metselaar, H.S.C. Electrophoretic deposition of calcium silicate-reduced graphene oxide composites on titanium substrate. J. Eur. Ceram. Soc. 2016, 36, 319-332. [CrossRef]

30. Shi, Y.Y.; Li, M.; Liu, Q.; Jia, Z.J.; Xu, X.C.; Cheng, Y.; Zheng, Y.F. Electrophoretic deposition of graphene oxide reinforced chitosan-hydroxyapatite nanocomposite coatings on ti substrate. J. Mater. Sci. Mater. Med. 2016, 27, 48. [CrossRef] [PubMed]

31. Sharma, H.; Mondal, S. Functionalized graphene oxide for chemotherapeutic drug delivery and cancer treatment: A promising material in nanomedicine. Int. J. Mol. Sci. 2020, 21, 6280. [CrossRef]

32. Rykowska, I.; Nowak, I.; Nowak, R. Drug-eluting stents and balloons-materials, structure designs, and coating techniques: A review. Molecules 2020, 25, 4624. [CrossRef]

33. Kovtun, A.; Jones, D.; Dell'Elce, S.; Treossi, E.; Liscio, A.; Palermo, V. Accurate chemical analysis of oxygenated graphene-based materials using x-ray photoelectron spectroscopy. Carbon 2019, 143, 268-275. [CrossRef]

34. Qin, H.; Gong, T.; Cho, Y.; Lee, C.; Kim, T. A conductive copolymer of graphene oxide/poly(1-(3-aminopropyl)pyrrole) and the adsorption of metal ions. Polym. Chem. 2014, 5, 4466-4473. [CrossRef]

35. Karthik, P.; Vinoth, R.; Zhang, P.; Choi, W.; Balaraman, E.; Neppolian, B. П- $\pi$ interaction between metal-organic framework and reduced graphene oxide for visible-light photocatalytic h2 production. ACS Appl. Energy Mater. 2018, 1, 1913-1923. [CrossRef]

36. Xu, X.; Li, W.; Wang, Y.; Dong, G.; Jing, S.; Wang, Q.; Feng, Y.; Fan, X.; Ding, H. Study of the preparation of cu-tic composites by reaction of soluble ti and ball-milled carbon coating tic. Results Phys. 2018, 9, 486-492. [CrossRef]

37. Hwang, M.-J.; Kim, M.-G.; Kim, S.; Kim, Y.C.; Seo, H.W.; Cho, J.K.; Park, I.-K.; Suhr, J.; Moon, H.; Koo, J.C.; et al. Cathodic electrophoretic deposition (epd) of phenylenediamine-modified graphene oxide (go) for anti-corrosion protection of metal surfaces. Carbon 2019, 142, 68-77. [CrossRef] 
38. Zielinski, A.; Bartmanski, M. Electrodeposited biocoatings, their properties and fabrication technologies: A review. Coatings 2020, 10, 782. [CrossRef]

39. Nemee, P.; Jaitanong, N.; Narksitipan, S. Surface modification of low carbon steel by using electrophoretic deposition technique with graphene oxide powder. Solid State Phenom. 2020, 302, 1-7. [CrossRef]

40. Shayesteh Moghaddam, N.; Taheri Andani, M.; Amerinatanzi, A.; Haberland, C.; Huff, S.; Miller, M.; Elahinia, M.; Dean, D. Metals for bone implants: Safety, design, and efficacy. Biomanuf. Rev. 2016, 1, 1. [CrossRef]

41. Dehghanghadikolaei, A.; Fotovvati, B. Coating techniques for functional enhancement of metal implants for bone replacement: A review. Materials 2019, 12, 1795. [CrossRef]

42. Su, J.; Du, Z.; Xiao, L.; Wei, F.; Yang, Y.; Li, M.; Qiu, Y.; Liu, J.; Chen, J.; Xiao, Y. Graphene oxide coated titanium surfaces with osteoimmunomodulatory role to enhance osteogenesis. Mater. Sci. Eng. C 2020, 113, 110983. [CrossRef]

43. Qiu, J.; Geng, H.; Wang, D.; Qian, S.; Zhu, H.; Qiao, Y.; Qian, W.; Liu, X. Layer-number dependent antibacterial and osteogenic behaviors of graphene oxide electrophoretic deposited on titanium. ACS Appl. Mater. Interfaces 2017, 9, 12253-12263. [CrossRef] [PubMed]

44. Tao, B.; Chen, M.; Lin, C.; Lu, L.; Yuan, Z.; Liu, J.; Liao, Q.; Xia, Z.; Peng, Z.; Cai, K. Zn-incorporation with graphene oxide on ti substrates surface to improve osteogenic activity and inhibit bacterial adhesion. J. Biomed. Mater. Res. A 2019, 107, 2310-2326. [CrossRef]

45. Allen, M.J.; Tung, V.C.; Kaner, R.B. Honeycomb carbon: A review of graphene. Chem. Rev. 2010, 110, 132-145. [CrossRef]

46. Song, M.-J.; Amirian, J.; Linh, N.T.B.; Lee, B.-T. Bone morphogenetic protein-2 immobilization on porous pcl-bcp-col composite scaffolds for bone tissue engineering. J. Appl. Polym. Sci. 2017, 134, 45186. [CrossRef]

47. Pugalenthi, R.; Arunachalam, P.; Amalraj, S.; Rathinavel, J.; Subramaniyan, D.S.; Bhagavathsingh, J.; Samuel, V. Covalent grafting of n-containing compound with graphene oxide: Efficient electrode material for supercapacitor. Chem. Sci. Eng. Res. 2019, 1. [CrossRef]

48. Liang, X.; Zhong, J.; Shi, Y.; Guo, J.; Huang, G.; Hong, C.; Zhao, Y. Hydrothermal synthesis of highly nitrogen-doped few-layer graphene via solid-gas reaction. Mater. Res. Bull. 2015, 61, 252-258. [CrossRef] 